E-ISSN : 2549-6581

DOI: 10.21776/ub.JOIM.2021.005.01.3

OPEN ACCESS

Artikel Hasil Penelitian

Journal of Issues in Midwifer

Diterima : 18 Desember 2020

Direview : 8 Maret 2021

Dimuat : April-Juli 2021

\title{
Pengaruh Video Modelling terhadap Kemampuan Toileting pada Anak Usia Toddler di Kelompok Belajar (KB) Permata Bunda Padasan
}

\author{
Tiara Putri Ryandini ${ }^{\left.1^{*}\right)}$, Dyah Pitaloka ${ }^{2}$, Novia Dwi Astuti ${ }^{3}$ \\ 1*) Prodi Ners, Institut IImu Kesehatan Nahdlatul Ulama Tuban, tiara.putriryandini16@gmail.com, \\ $+6281326634660$ \\ ${ }^{2}$ Prodi Ners, Institut IImu Kesehatan Nahdlatul Ulama Tuban, dyahpitaloka385@gmail.com \\ ${ }^{3}$ Prodi Ners, Institut Ilmu Kesehatan Nahdlatul Ulama Tuban, noviastikesnu@gmail.com
}

\begin{abstract}
At the time toddler, this is the right time for parents to teach children to perform toileting. Children who have not been able to perform toileting properly because of the ability of a child who is not robust like, not yet accustomed to sitting or squatting on the toilet, have not been able to remove his trousers, and some children do who do not know how toileting, requires a method or way that is easily understood by children in teaching toileting, one of which is by video modeling. This study uses Analytical Experimental Design with one-group pretest-posttest design conducted on 34 respondents. The sampling technique uses probability sampling with a simple random sampling method. The instruments used were toileting ability questionnaire and video modeling. The results showed that the ability of child toileting before being given video modeling most of the respondents had sufficient ability, and after being given video modeling almost all respondents had good abilities. This is evidenced by the Wilcoxon test obtained p-value = $0,000(\alpha<0.05)$ where $0,000<0.05$ then there is an influence of video modeling on the ability of toileting toddler children in the Bunda Padasan Permata study group. From the results of this study, it can be concluded that video modeling can be used as an alternative to toileting learning media in toddler-age children.
\end{abstract}

Keywords: toileting ability, video modeling.

\begin{abstract}
ABSTRAK
Pada masa toddler inilah waktu yang tepat bagi orang tua untuk mengajarkan anak dalam melakukan toileting. Anak yang belum dapat melakukan toileting dengan benar karena kemampuan anak yang masih belum adekuat seperti, belum terbiasa untuk duduk atau jongkok di toilet, belum bisa melepas celananya sendiri, serta ada anak yang belum mengetahui cara toileting, membutuhkan suatu metode atau cara yang mudah dimengerti oleh anak dalam mengajarkan toileting, salah satunya yaitu dengan video modelling. Penelitian ini menggunakan desain Analitik Eksperimen design dengan jenis one-group pretest-posttest design yang dilakukan pada 34 responden. Tehnik pengambilan sampel menggunakan probability sampling dengan metode simple random sampling. Instrumen yang digunakan yaitu kuesioner kemampuan toileting dan video modelling. Hasil penelitian menunjukkan bahwa kemampuan toileting anak sebelum diberikan video modeling sebagian besar responden memiliki kemampuan cukup, dan setelah diberikan
\end{abstract}


video modelling hampir seluruh responden memiliki kemampuan baik. Hal ini dibuktikan dengan uji wilcoxon diperoleh nilai $p$-value $=0,000(\alpha<0,05)$ dimana 0,000 $<0,05$ maka ada pengaruh video modelling terhadap kemampuan toileting anak usia toddler di Kelompok Belajar (KB) Permata Bunda Padasan. Dari hasil penelitian dapat disimpulkan bahwa video modelling dapat digunakan sebagai alternatif untuk media pembelajaran toileting pada anak usia toddler.

Kata kunci: kemampuan toileting, video modelling.

*Korespondensi: Tiara Putri Ryandini Surel: tiara.putriryandini16@gmail.com

\section{PENDAHULUAN}

Pertumbuhan

dan

perkembangan anak berlangsung sangat cepat pada usia 1-3 tahun (toddler) meliputi kemampuan mobilitas fisik, kognitif, afektif, dan psikomotor. Kemampuan kognitif anak yang dimaksud adalah anak mulai memahami waktu seperti kapan harus BAB atau BAK, sedangkan kemampuan afektif yaitu belajar konsep rasa senang, sedih, marah, dan lain-lain, serta kemampuan motorik anak yaitu mulai bisa jongkok, belajar mengenakan dan melepas pakaian, mencuci tangan sendiri serta belajar mengendalikan pembuangan kotoran tubuh (toileting). Ada anak yang belum dapat melakukan toileting dengan benar karena kemampuan anak yang masih belum adekuat, seperti belum terbiasa untuk duduk atau jongkok di toilet, belum bisa melepas celananya sendiri, belum mengetahui tempat dan waktu $B A B$ atau BAK, serta ada anak yang belum mengetahui cara toileting. Dampak ketika anak gagal dalam toileting yaitu anak menjadi tidak displin dan manja, serta cenderung bersifat retentive dimana anak cenderung bersikap keras kepala bahkan kikir (1)

Kejadian mengompol lebih besar pada anak laki-laki yaitu $60 \%$ dan anak perempuan $40 \%$. Penelitian pada anak 10.960 anak di
Amerika, pravelensi mengompol pada anak laki-laki yang berusia 7 sampai 10 tahun adalah 6\% dan $3 \%$. Statistik menunjukkan, 25\% anak mengompol pada usia 5 tahun akan menurun menjadi $5 \%$ sampai pada usia 10tahun, dan tinggal $2 \%$ pada usia 10-15 tahun (2).

Kemampuan toileting anak dipengaruhi oleh dua faktor yaitu faktor kemampuan anak dan faktor motivasi orang tua, faktor kemampuan anak meliputi kognitif, afektif, psikomotor. Kemampuan toileting anak yang belum adekuat seperti kemampuan koginitif anak belum memahami waktu kapan harus $B A B$ atau $B A K$, dan belum mengetahui cara $B A B$ atau BAK di toilet. Untuk kemampuan afektif anak belum adekuat dapat dilihat saat $B A B$ atau BAK anak masih rewel, menangis, dan tidak mau ditinggal ketika BAB atau BAK, sedangkan kemampuan psikomotor yaitu anak belum dapat melakukan tindakan toileting secara mandiri seperti melapas celana masih dilakukan oleh orang tua. Kemampuan anak dalam toileting yang belum adekuat, membutuhkan suatu metode atau cara yang mudah dimengerti oleh anak dalam mengajarkan toileting. Penggunaan metode yang mudah dimengerti akan mempengaruhi keberhasilan dalam mengajarkan konsep toileting pada anak, salah satunya yaitu dengan video modelling. Media ini 
memberikan stimulus pada pendengaran dan penglihatan sehingga hasil yang diharapkan lebih maksimal dalam meningkatkan kemampuan anak, yaitu anak menjadi tahu cara toileting dan kemudian anak dapat menerapkanya (4).

Pembelajaran toileting bisa dilakukan dengan cara lisan dan modelling. Untuk menambah keberhasilan dalam pembelajaran video modelling dan untuk meningkatkan kemampuan anak dalam toileting, perlu adanya dukungan serta latihan dari orang tua dan keaktifan anak dalam melakukan toileting (4).

Adapun tujuan penelitian adalah untuk mengetahui pengaruh video modelling terhadap kemampuan toileting anak usia toddler di Kelompok Belajar (KB) Permata Bunda Padasan.

\section{METODE PENELITIAN}

Desain yang digunakan dalam penelitian ini adalah analitik eksperimental dengan jenis onegroup pretest-posttest design yaitu penelitian yang bertujuan untuk menentukan pengaruh sebab akibat dengan cara melibatkan satu kelompok eksperimen (5).

Responden dalam penelitian ini adalah sebagian siswa-siswi $\mathrm{KB}$ Permata Bunda yang diambil menggunakan teknik simple random sampling terhadap kuesioner kemampuan toileting yang mencakup aspek kognitif, afektif, dan psikomotor yang sudah dinyatakan valid. Nilai valid didapatkan dari hasil $r$ hitung $\geq r$ tabel, pada uji reliabilitas di peroleh $r$ hitung (cronbach's alpha) dari pernyataan kognitif sebesar $0,863, r$ hitung (cronbach's alpha) afektif sebesar 0,907 dan $r$ hitung (cronbach's alpha) psikomotor 0 , 930 dan instrumen variabel independen menggunakan metode video modelling tentang toileting

Pengumpulan data pada penelitian ini menggunakan data primer dimulai dengan izin dari institusi dan dari pihak KB Permata Bunda.

Peneliti menemui calon responden dan melakukan penjelasan, kemudian meminta orang tua calon responden untuk menandatangani surat pernyataan awal, selanjutnya peneliti melakukan penelitian. Penelitian dilakukan selama kurang lebih 28 hari dengan 6 kali pemutaran video, data yang digunakan peneliti yaitu data pada pre dan post kegiatan. Penelitian ini menggunakan analisa data dengan uji wilcoxon sign rank test.

Sampling dengan metode pengembalian, setiap nomor yang terpilih harus dikembalikan lagi sehingga setiap sample memiliki prosentase kesempatan yang sama untuk terpilih maupun tidak terpilih sebagai sample. Sejumlah 34 orang dijadikan sampel dalam penelitian.

Instrumen yang digunakan pada penelitian ini adalah kuesioner kemampuan toileting anak yang mencakup aspek kognitif, afektif, dan psikomotor. Lembar kuesioner sudah dilakukan uji validitas dan reliabilitas. 


\section{HASIL PENELITIAN}

Gambaran umum responden menjelaskan tentang jenis kelamin responden dan riwayat pendidikan orang tua responden dalam bentuk tabel berikut.

1. Jenis Kelamin Responden

Tabel 1 Distribusi Jenis Kelamin Responden Kelas A di KB Permata Bunda Padasan

\begin{tabular}{|c|c|c|c|}
\hline No & Jenis Kelamin & $f$ & Prosentase (\%) \\
\hline 1 & Laki-laki & 13 & $38,2 \%$ \\
\hline 2 & Perempuan & 21 & $61,8 \%$ \\
\hline & Jumlah & 34 & $100 \%$ \\
\hline
\end{tabular}

Berdasarkan tabel 1 menunjukkan bahwa sebagian besar responden di KB Permata

Bunda Padasan Kelas A berjenis kelamin perempuan dengan jumlah $21(61,8 \%)$ responden.

2. Usia Responden

Tabel 2 Distribusi Usia Responden Kelas A di KB Permata Bunda Padasan

\begin{tabular}{|c|c|c|c|}
\hline No & Usia & $f$ & Prosentase (\%) \\
\hline 1 & 36 bulan & 34 & $100 \%$ \\
\hline 2 & 24 bulan & 0 & $0 \% \%$ \\
\hline & Jumlah & 34 & $100 \%$ \\
\hline
\end{tabular}

Berdasarkan tabel 2 menunjukkan bahwa seluruhnya responden di $\mathrm{KB}$ Permata Bunda Padasan Kelas A berusia 36 bulan dengan jumlah 34 $(100 \%)$ responden.

\section{Riwayat Pendidikan Orang Tua Responden}

\section{Tabel 3 Distribusi Riwayat Pendidikan Orang Tua Responden Kelas A di} KB Permata Bunda Padasan

\begin{tabular}{|c|c|c|c|}
\hline No & Pendidikan Terakhir & $f$ & Prosentase (\%) \\
\hline 1 & SD/Sederajat & 4 & $11,77 \%$ \\
\hline 2 & SMP/Sederajat & 17 & $50 \%$ \\
\hline 3 & SMA/Sederajat & 11 & $32,35 \%$ \\
\hline 4 & S1 & 2 & $5,88 \%$ \\
\hline & Jumlah & 34 & $100 \%$ \\
\hline
\end{tabular}

Berdasarkan tabel 3 menunjukkan bahwa setengahnya pendidikan terakhir orang tua siswa-siswi KB Permata Bunda Padasan tamatan SMP/Sederajat dengan jumlah 17 (50\%).Data khusus yang diperoleh pada penelitian ini meliputi kemampuan toileting anak usia toddler sebelum dan sesudah diberikan perlakuan serta analisis pengaruh video modelling terhadap kemampuan toileting pada anak usia toddler di KB Permata Bunda Padasan. 
4. Hasil Kemampuan Toileting Anak Usia Toddler Sebelum Diberikan Video Modelling di KB Permata Bunda Padasan

Tabel 4 Kemampuan Toileting Anaka usia Toddler Kelas A Sebelum Diberikan Video Modelling di KB Permata Bunda Padasan

\begin{tabular}{lcc}
\hline \multicolumn{1}{c}{ Tingkat Kemampuan Toileting } & $\boldsymbol{f}$ & Prosentase (\%) \\
Anak & 0 & $0 \%$ \\
Sangat Baik & 11 & $32,35 \%$ \\
Baik & 18 & $52,94 \%$ \\
Cukup & 5 & $14,71 \%$ \\
Kurang & 0 & $0 \%$ \\
Sangat Kurang & 34 & $100 \%$ \\
\hline \multicolumn{2}{c}{ Jumlah } &
\end{tabular}

Sumber: Data Primer Peneliti, Tahun 2020

Berdasarkan tabel 4 menunjukkan bahwa kemampuan toileting anak usia toddler kelas A di KB Permata Bunda Padasan sebelum diberikan terapi Video Modelling (toileting) sebagian besar responden memiliki kemampuan cukup dalam toileting yang berjumlah 18 (52,94\%) anak.

5. Hasil Kemampuan Toileting Anak Usia Toddler Sesudah Diberikan Video Modelling di KB Permata Bunda Padasan.

Tabel 5 Kemampuan Toileting Anak usia Toddler Kelas A Sesudah Diberikan Video Modelling di KB Permata Bunda Padasan

\begin{tabular}{|c|c|c|}
\hline $\begin{array}{c}\text { Tingkat Kemampuan Toileting } \\
\text { Anak }\end{array}$ & $f$ & Prosentase (\%) \\
\hline Sangat Baik & 2 & $5,88 \%$ \\
\hline Baik & 32 & $94,12 \%$ \\
\hline Cukup & 0 & $0 \%$ \\
\hline Kurang & 0 & $0 \%$ \\
\hline Sangat Kurang & 0 & $0 \%$ \\
\hline Jumlah & 34 & $100 \%$ \\
\hline
\end{tabular}

Sumber: Data Primer Peneliti, Tahun 2020

Berdasarkan tabel 5 menunjukkan bahwa kemampuan toileting anak usia toddler kelas A di KB Permata Bunda Padasan sesudah diberikan terapi Video Modelling (toileting) hampir seluruh responden memiliki kemampuan baik dalam toileting yang berjumlah $32(94,12 \%)$ anak. 
6. Analisis Pengaruh Video Modelling terhadap Kemampuan Toileting pada Anak Usia Toddler di KB Permata Bunda Padasan

Tabel 6 Tabel Silang Pengaruh Video Modelling terhadap Kemampuan Toileting pada Anak Usia Toddler di KB Permata Bunda Padasan

\begin{tabular}{lcccccc}
\hline Video Modelling & \multicolumn{3}{c}{ Kemampuan Toileting } & Total \\
\hline $\begin{array}{c}\text { Penayangan } \\
\text { video modelling }\end{array}$ & $\begin{array}{c}\text { Sangat } \\
\text { Kurang }\end{array}$ & Kurang & Cukup & Baik & Sangat Baik & \\
\hline Pre-test & 0 & 5 & 18 & 11 & 0 & 34 \\
& $(0 \%)$ & $(14,71 \%)$ & $(52,94 \%)$ & $32,35 \%$ & $(0,0 \%)$ & $(100 \%)$ \\
Post-test & 0 & 0 & 0 & 32 & 2 & 34 \\
& $(0 \%)$ & $(0 \%)$ & $(0 \%)$ & $(94,12 \%)$ & $(5,88 \%)$ & $(100 \%)$ \\
\hline
\end{tabular}

Sumber : Data Primer Peneliti, Tahun 2020

\begin{tabular}{|c|c|c|c|c|c|}
\hline & & & \multicolumn{2}{|c|}{ Post Test } & \multirow[t]{2}{*}{ Total } \\
\hline & & & Sangat Baik & Baik & \\
\hline \multirow[t]{15}{*}{ Pre Test } & \multirow[t]{5}{*}{ baik } & Count & 1 & 10 & 11 \\
\hline & & Expected Count & 6 & 10,4 & 11,0 \\
\hline & & $\%$ within Pre Test & $9,1 \%$ & $90,9 \%$ & $100,0 \%$ \\
\hline & & $\%$ within Post Test & $50,0 \%$ & $31,3 \%$ & $32,4 \%$ \\
\hline & & $\%$ of Total & $2,9 \%$ & $29,4 \%$ & $32,4 \%$ \\
\hline & \multirow[t]{5}{*}{ cukup } & Count & 1 & 17 & 18 \\
\hline & & Expected Count & 1,1 & 16,9 & 18,0 \\
\hline & & $\%$ within Pre Test & $5,6 \%$ & $94,4 \%$ & $100,0 \%$ \\
\hline & & $\%$ within Post Test & $50,0 \%$ & $53,1 \%$ & $52,9 \%$ \\
\hline & & $\%$ of Total & $2,9 \%$ & $50,0 \%$ & $52,9 \%$ \\
\hline & \multirow[t]{5}{*}{ kurang } & Count & 0 & 5 & 5 \\
\hline & & Expected Count &, 3 & 4,7 & 5,0 \\
\hline & & $\%$ within Pre Test & $0,0 \%$ & $100,0 \%$ & $100,0 \%$ \\
\hline & & $\%$ within Post Test & $0,0 \%$ & $15,6 \%$ & $14,7 \%$ \\
\hline & & $\%$ of Total & $0,0 \%$ & $14,7 \%$ & $14,7 \%$ \\
\hline \multirow[t]{5}{*}{ Total } & & Count & 2 & 32 & 34 \\
\hline & & Expected Count & 2,0 & 32,0 & 34,0 \\
\hline & & $\%$ within Pre Test & $5,9 \%$ & $94,1 \%$ & $100,0 \%$ \\
\hline & & $\%$ within Post Test & $100,0 \%$ & $100,0 \%$ & $100,0 \%$ \\
\hline & & $\%$ of Total & $5,9 \%$ & $94,1 \%$ & $100,0 \%$ \\
\hline
\end{tabular}

Berdasarkan tabel 6 menunjukkan bahwa kemampuan anak sebelum diberikan video modelling sebagian besar responden memiliki kemampuan cukup dalam toileting yang berjumlah $18(52,94 \%)$ anak. Sedangkan sesudah diberikan video modelling hampir seluruh responden memiliki kemampuan baik dalam toileting yang berjumlah 32 $(94,12 \%)$ anak. 
PEMBAHASAN

Identifikasi Kemampuan Toileting Anak Usia Toddler Sebelum Diberikan Video Modelling di KB Permata Bunda Padasan.

Hasil penelitian menunjukkan bahwa sebagian besar responden sudah menerapkan toileting dalam kehidupan sehari-hari, pada saat pre-test atau sebelum diberikan perlakuan sebagian besar responden memiliki kemampuan toileting cukup yang berjumlah 18 (52,94\%) anak.

Toileting adalah kemampuan pada anak dalam membiasakan aktivitas buang air kecil (BAK) dan buang air besar (BAB) pada tempatnya (toilet), BAB atau BAK termasuk dalam perkembangan psikomotorik karena membutuhkan kematangan otot-otot pada daerah pembuangan kotoran (anus dan saluran kemih). Kemampuan tersebut hendaknya dimulai pada waktu berusia 15 bulan dan kurang bijaksana bila anak pada usia kurang dari 15 bulan karena dapat menimbulkan pengalamanpengalaman traumatik. Toileting merupakan kemampuan moral yang pertama kali diterima anak dan sangat berpengaruh pada perkembangan moral anak selanjutnya (6) .

Penelitian ini sesuai dengan penelitian yang telah dilakukan oleh Faikoh (2014) yang dilakukan untuk mengetahui pengaruh modelling media video terhadap peningkatan kemampuan toilet training pada anak retardasi mental usia 5-7 tahun menunjukkan bahwa sebelum diberikan perlakuan sebagian besar responden memiliki kategori kemampuan yang tidak mampu (7).

Pada penelitian ini terdapat beberapa faktor internal yang mempengaruhi kemampuan anak dalam toileting yaitu aspek kognitif, afektif dan psikomotor, dimana kemampuan koginitif anak belum memahami waktu seperti kapan harus $B A B$ atau BAK, dan belum mengetahui cara BAB atau BAK di toilet. Untuk kemampuan afektif anak belum adekuat dapat dilihat saat $B A B$ atau BAK anak masih rewel, menangis, dan tidak mau ditinggal ketika BAB atau BAK, sedangkan kemampuan psikomotor yaitu anak belum dapat melakukan tindakan toileting secara mandiri seperti melapas celana masih dilakukan oleh orang tua, sehingga dimana anak yang belum mengetahui cara toileting yang benar, maka dia akan bersikap rewel dan masih menangis, karena anak belum tahu cara toileting yang benar dan masih rewel maka anak masih memerlukan bantuan total dari orang tuanya.

\section{Identifikasi Kemampuan}

Toileting Anak Usia Toddler Sesudah Diberikan Video Modelling di KB Permata Bunda Padasan

Berdasarkan hasil penelitian setalah diberikan video modelling atau pada saat post test di KB Permata Bunda Padasan didapatkan bahwa hampir seluruh responden mengalami peningkatan kemampuan yang berjumlah 32 $(94,12 \%)$ anak.

Dari hasil pemaparan di atas diketahui kemampuan toileting pada anak usia toddler di KB Permata Bunda Padasan mengalami peningkatan setelah diberikan video modelling (tentang toileting). Ini diperkuat dengan adanya teori yang menjelaskan bahwa pada dasarnya kemampuan toileting pada anak 
usia prasekolah mempunyai beberapa penatalaksanaan, salah satunya yaitu dengan video modelling teknik modelling adalah teknik yang bertujuan untuk mempelajari perilaku baru dengan mengamati model dan mempelajari keterampilannya. Proses terapeutik dalam bentuk modelling akan membantu atau memengaruhi serta memperkuat perilaku yang lemah atau memperkuat perilaku yang siap dipelajari dan memperlancar respon, Media ini memberikan stimulus pada pendengaran dan penglihatan sehingga hasil yang diharapkan lebih maksimal dalam meningkatkan kemampuan anak, yaitu anak menjadi tahu cara toileting, kemudian anak dapat menerapkannya (8).

Berdasarkan hasil penelitian dan teori yang ada peneliti berpendapat bahwa hampir seluruhnya responden mempunyai kemampuan toileting yang baik. Selama kurang lebih satu bulan hampir seluruh kemampuan responden baik laki-laki maupun perempuan berusia 3 tahun meningkat baik dari aspek kognitif, afektif maupun psikomotor anak. Pada aspek kognitif anak mengalami peningkatan yaitu anak sudah mengetahui tempat untuk BAB atau BAK, waktu ketika BAB atau $\mathrm{BAK}$, memberitahu orang tua jika ingin $B A B$ atau BAK, dan mengetahui langkah pertama jika ingin BAB atau BAK. Perkembangan pada aspek afektif yaitu anak tidak rewel ketika BAB atau BAK ditoilet, anak sudah mau ditinggal jika $B A B$ atau BAK ditoilet, dan ketika ingin tidur anak akan BAK terlebih dahulu. Untuk perkembangan aspek psikomotor anak sudah bisa melepas dan memakai celana ketika ingin BAB atau BAK secara mandiri, jongkok ditoilet secara mandiri, cebok stelah BAK, menyiram toilet setelah BAK, dan mencuci tangannya setelah BAB atau BAK.

Analisis Pengaruh Video Modelling terhadap Kemampuan Toileting pada Anak Usia Toddler di KB Permata Bunda Padasan

Analisa dalam penelitian ini menggunakan Uji Wilcoxon Sighn Rank Test dengan tingkat kemaknaan $\alpha=0,05$ dan perhitungannya dilakukan dengan menggunakan aplikasi SPSS for Windows didapatkan hasil nilai signifikan (2-tailed) $=0,000$ dimana $0,000<0,05$ maka $\mathrm{H} 1$ diterima sehingga dapat disimpulkan bahwa terdapat pengaruh video modelling terhadap kemampuan toileting pada anak usia toddler di KB Permata Bunda Padasan.

Adanya perubahan yang menunjukkan bahwa pemutaran video modelling terhadap kemampuan toileting anak usia toddler di KB Permata Bunda Padasan disebabkan oleh pemutaran video modelling yang dilakukan secara rela dan dirasa menyenangkan sehingga dapat di terima dengan baik oleh responden. $\mathrm{Hal}$ ini diperkuat dari pernyataan bahwa penggunaan teknik video modelling juga dianjurkan untuk membantu anak dalam proses pembelajaran toileting. Media ini memberikan stimulus pada pendengaran dan penglihatan sehingga hasil yang diharapkan lebih maksimal dalam meningkatkan kemampuan anak, yaitu anak menjadi tahu cara toileting dan kemudian anak dapat menerapkannya (3). 
Penelitian ini sesuai dengan penelitian yang dilakukan oleh Rahmatika (2014) untuk mengetahui perbedaan pengaruh tehnik modelling video dan teknik bercerita terhadap kemampuan toilet training anak prasekolah. Hasil penelitian menunjukkan bahwa $p$-value 0,000 yang artinya $p$-value $<0,05$ sehingga ada perbedaan pengaruh teknik modelling video dan tehnik bercerita terhadap kemampuan toilet training anak prasekolah. Tehnik modelling video lebih dapat meningkatkan kemampuan toilet training anak prasekolah (9).

Penelitian ini memiliki beberapa keterbatasan. Namun diharapkan tidak mempengaruhi tujuan utama dari penelitian. Peneliti menyadari bahwa ada faktor lain yang tidak dapat di kesampingkan oleh peneliti yaitu pengalaman responden, motivasi, serta pola asuh orang tua yang mengajarkan tentang toileting pada anaknya, serta lingkungan yang mendukung.

\section{SIMPULAN}

Dari hasil penelitian ini dapat disimpulkan bahwa :

1. Kemampuan toileting anak sebelum diberikan video modelling di KB Permata Bunda Padasan sebagian besar responden memiliki kemampuan cukup dalam toileting.

2. Kemampuan toileting anak sesudah diberikan video modelling di KB Permata Bunda Padasan hampir seluruh responden memiliki kemampuan baik dalam toileting.

3. Ada perbedaan kemampuan anak usia toddler sebelum dan sesudah diberikan video modelling tentang toileting di KB Permata Bunda Padasan.

\section{DAFTAR PUSTAKA}

1. Hidayat AA. Pengantar Keperawatan Anak 1. Jakarta Selatan: Salemba Medika; 2011.

2. Fitricilia $M$, Umboh $A$, Kaunang D. Hubungan Enuresis Dengan Infeksi Saluran Kemih Pada Anak Usia 6-8 Tahun Di Sd Negeri Malalayang. $\mathrm{J}$ e-Biomedik. 2013;1(1).

3. Anggita Kesuma Putri. Hubungan Tingkat Pengetahuan Ibu Tentang Toilet Training Terhadap Pelaksanaan Toilet Training Pada Anak Usia Toddler Di Kelurahan Sewu Surakarta. J Chem Inf Model. 2016;53(9):1689-99.

4. Luh Putu Karsi Ekayani, Francisca Shanti Kusumaningsih PSNA. Efektivitas Penyuluhan Dengan Audio Visual Terhadap Keberhasilan Toilet Training Pada Anak Umur 2-3 Tahun. 2019;8:124-32.

5. Nursalam. Metodelogi Penelitian IImu Keperawatan: Pendekatan Praktis. 4th ed. Lestasi PP, editor. Jakarta Selatan: Salemba Medika; 2016.

6. Dewi LPMK, Parmiti DP, Jampe IN. Pengembangan Video Berbasis Masalah Pada Mata Pelajaran Pjok Untuk Meningkatkan Hasil Belajar Siswa Kelas V. e-Journal Edutech Univ Pendidik Ganesha [Internet]. 2016;5(2). Available from: https://ejournal.undiksha.ac.id/ 
index.php/JEU/article/view/76 70

7. Debora, Arisska, Sitompul DR. Pengaruh Terapi Mewarnai Gambar Dengan Pasir Warna Terhadap Kecemasan Anak Prasekolah 3-5 Tahun. J Keperawatan Suaka Insa. 2018;3(2):1-7.

8. Rusdiana H, Sumardi K, Arifiyanto ES. Evaluasi Hasil Belajar Menggunakan Penilaian Autentik Pada Mata Pelajaran Kelistrikan Sistem Refrigerasi. J Mech Eng Educ. 2016;1(2):274.

9. Rahmatika Ammelda, Riri Novayelinda E. Pengaruh Modelingmedia Video Dan Gambar Terhadap Peningkatan Kemampuan Toilet Training Pada Anak Toddler. 2014;1-3.

10. Kemendikbud. 2014. Permendikbud Nomor 104 Tahun $2014 \quad$ Tentang Penilaian Hasil Belajar Oleh Pendidik Pada Pendidikan Dasar dan Pendidikan Menengah. Jakarta :
Kementerian Pendidikan Kebudayaan dan RI

11. Prastowo Andi, 2012. Panduan Kreatif Membuat Bahan Ajar Inovatif. Yogyakarta: Diva Press

12. Soetjiningsih. 2014. Tumbuh Kembang Anak. Jakarta: Penerbit Buku Kedokteran EGC.

13. Sugiyono, 2013. Metodologi Penelitian Pendidikan Pendekatan Kuantitatif, Kualitatif dan R\&D. Bandung: Alfabeta.

14. Kyle \& Carman. (2015). Buku Ajar Keperawatan Pediatri Edisi 2. Diterjemahkan Oleh Devi Yulianti Dan Dwi Widiarti. Jakarta: EGC.

15. Kyle, Terii \& Carman, Susan. (2014). Buku Ajar Keperawatan Pediatri (Estu Tiar, Sari Isneini, Barrarah Bariid, Penerjemah). Jakarta : EGC. 